https://ink.springer.com/article/10.1007/s11061-017-9532-x

"This is a post-peer-review, pre-copyedit version of an article published in Neophilologus. The final authenticated version is available online at: http://dx.doi.org/ 10.1007/s11061-017-9532-x"

\title{
Una invectiva inédita contra Gracias y desgracias del ojo del culo de Quevedo*
}

\author{
María José Alonso Veloso \\ Universidad de Santiago de Compostela
}

En la década comprendida entre 1626 y 1635 se sucedieron las invectivas contra las obras y la persona de Francisco de Quevedo. Su primer biógrafo, Pablo de Tarsia, sintetizaba así los ataques sufridos y la supuesta reacción del escritor tras la difusión de la más agresiva de todas, El tribunal de la justa venganza, ${ }^{1}$ publicada en 1635 :

No faltó a este varón ilustre [...] la fortuna [...] en haberse levantado contra sus escritos Zoilos detractadores que, con la infeliz censura de su pluma, enlutada de envidia, hicieron sobresalir más claramente lo cándido de tan soberanos ingenios (1988, p. 48)

Habiendo visto el Almirante de Castilla, príncipe laureado de victorias, y otros Señores de la Corte, sus amigos, el libro del Tribunal, pertrechado con osadía y atrevimiento, y persuadiendo todos a don Francisco le diese el asalto con el cañón de su pluma, se excusó de la empresa diciendo: "Eso fuera, señores, ser tan ruin yo como los que le escribieron; seguiré al Sabio, que me aconseja no responder al loco según su locura (1988, p. 53).

La secuencia de la difusión de tales escritos, que pretenden frenar la circulación de los textos quevedianos con la intervención de la Inquisición, es bien conocida: después de que en el año 1610 se le hubiese negado autorización para imprimir sus tres primeros Sueños, Morovelli de la Puebla (1932) publicó una invectiva contra Política de Dios en 1626; Pacheco de Narváez (1932), por su parte, divulgó hacia 1629-1630 un

\footnotetext{
" Este artículo es resultado del proyecto de investigación "Edición crítica y anotada de la obra en prosa de Quevedo, IX" (MINECO, Excelencia 2015, FFI2015-64389-P; AEI/FEDER, UE).

${ }^{1}$ Bajo el seudónimo "Arnaldo Franco-Furt", apunta contra "los escritos de don Francisco de Quevedo, maestro de errores, doctor en desvergüenzas, licenciado en bufonerías, bachiller en suciedades, catedrático de vicios y protodiablo entre los hombres" (cito por la princeps, cuyo pie de imprenta supone licencia en Valencia, en la "Imprenta de los herederos de Felipe Mey", en 1635). Sobre las circunstancias de este texto y otros de la misma índole, véanse Fernández-Guerra (1852, p. LXVIII), Astrana Marín (1932, p. 1099), Plata (2006), Roncero (2008, p. 11-24), Tobar (2010), Rey (2014, p. 54), Laguna (2016) y Alonso Veloso (2017).
} 
Memorial contra varias obras quevedianas. ${ }^{2}$ En 1635 coincidieron tres nuevas e importantes impugnaciones: El tribunal de la justa venganza, de autor desconocido; y Memorial al rey nuestro señor y El retraído, de Juan de Jáuregui (1932b y 1932a). Previamente y en coincidencia con la publicación del Índice de Zapata de 1632, el propio Quevedo habría solicitado la retirada de la circulación de todas sus obras impresas antes de 1630, con el argumento de que habían sido difundidas sin su previa autorización, en un intento de evitar que recayese sobre ellas la condena inquisitorial (Jauralde 1999, p. 621).

Los datos conocidos sugerían hasta ahora, por tanto, que la primera invectiva conocida contra las obras impresas de Quevedo había sido las Anotaciones a la Política de Dios de Morovelli de Puebla (1932), que, entre otros efectos, provocó la sustitución del título inicial trimembre de la princeps del tratado político (Política de Dios, gobierno de Cristo y tiranía de Satanás) por el bimembre que prosperó en la tradición textual, como epígrafe autorizado por el escritor (con omisión de "tiranía de Satanás"). ${ }^{3}$

El presente artículo tiene como objetivo dar a conocer una invectiva hasta ahora inédita, que, por otra parte, podría encontrarse entre las más tempranas de las dirigidas expresamente contra un texto quevediano: titulada Excelencias y desagravios de los nobilísimos ojos de la cara, y zurriago contra el abogado del nefando ojo del culo, fue publicada sin fecha ni lugar de impresión, en $4^{\circ}$, con 8 páginas; se difundió además bajo un pseudónimo ("Escribiolas el bachiller Polvorín de Tras-Te-Riego"), como había sucedido con el texto burlesco de Quevedo contra el que se dirigía, Gracias y desgracias del ojo del culo, y como era práctica usual en este tipo de escritos.

Además de dar noticia del texto íntegro de la invectiva inédita, que aquí se edita modernizado en ortografía y puntuación, se ofrece información adicional sobre un ejemplar impreso desconocido de la obra burlesca quevediana satirizada, incluido en el mismo volumen facticio de la Biblioteca Valenciana "Nicolau Primitiu".

\footnotetext{
${ }^{2}$ Memorial denunciando al Tribunal de la Inquisición ciertas obras políticas y satírico-morales de don Francisco de Quevedo. El manuscrito autógrafo está hoy en paradero desconocido (Valladares 1999, p. 24), pero existen ediciones modernas de Menéndez Pelayo y Astrana. Véase también Peregrinos discursos y tardes bien empleadas, contra Politica de Dios, de Pacheco de Narváez (1999).

${ }^{3}$ Los ataques al título son semejantes en Morovelli, Anotaciones (1932, pp. 986-987); Pacheco de Narvávez, Memorial (1932, pp. 1044-1046); y Jáuregui, El retraído (1932, p. 1074). Véanse Crosby (1966), Díaz Martínez (2012, pp. 161-184) y Alonso Veloso (2015, pp. 124-126).
} 


\section{Información bibliográfica}

El discurso se conserva en un único ejemplar conocido, entre los fondos de la citada biblioteca. Este testimonio figura incluido en un volumen facticio, con signatura general XVII/773. Está integrado por seis textos diferentes (cinco a efectos de su catalogación), entre los cuales se encuentra un ejemplar del impreso de Gracias y desgracias del ojo del culo ${ }^{4}$ seguido de una hoja manuscrita de contenido relacionado, tampoco descritos hasta el momento:

1. Copia de una carta que el P. Antonio de Vieyra de la Compañia de Jesus escribio a vn señor obispo de la Orden de Predicadores. En Cordoua, 1686. 16 p.; $4^{\circ}$. Contiene: "Respuesta que de Thescoto Tamuertusi Patavino a una carta que Antonio de Vieyra Monopanto escrivio a un señor Obispo del orden de Predicadores". Signatura: XVII/773(1).

2. Recursos, ocursos y concursos sobre los discursos historicos de D. Francisco de Evaso / por el licenciado Abriguelo de Vargas. [S.l. : s.n., s.a.]. 15 p.; $4^{\text {o }}$. Signatura: XVII/773(2).

3. Gracias y desgracias del ojo del cvlo [texto impreso]: dirigidas a doña Iuana Mucha monton de carne, muger gorda por arrobas / Escriuiolas Ivan Lamas el del camison cagado. [S.1.: s.n., ca. 1626]. 16 p.; 4º Signatura: XVII/773(3) (lámina 1).

[Nos el Doctor D. Pedro Rodriguez de Montanches, Cathedratico de Prima de Medicina en la Universidad de Salamanca y Proto-medico de estos Reynos ... damos licencia al dicho [espacio en blanco para cumplimentar] para que delante o detrás de cualquier persona ... pueda sin contravenir, a las leyes de la cortesia espeler sus ventosidades ... ] [Manuscrito]. 1 h. Signatura: XVII/773(3 bis). ${ }^{5}$

\footnotetext{
4 Ofrezco más información sobre este nuevo testimonio también desconocido en el apartado de "Información bibliográfica" y, con más detalle, en otro lugar. El ejemplar del impreso no se encuentra entre las fuentes textuales descritas por Azaustre (2007).

${ }^{5}$ Debido a su curiosidad y brevedad, se transcribe su texto en un apéndice final.
} 


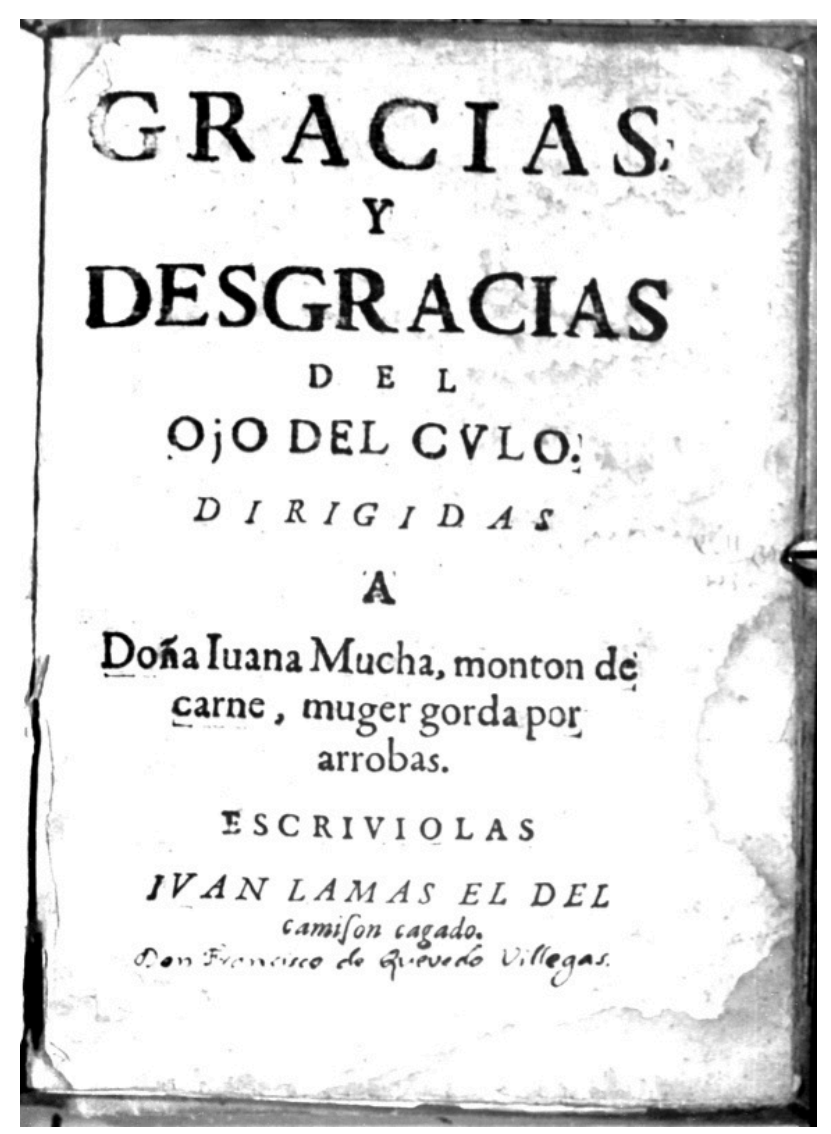

Lámina 1. Portada del ejemplar de Gracias y desgracias del ojo del culo en la Biblioteca Valenciana, donde se añade manuscrito el nombre de Quevedo.

4. Excelencias y desagravios de los nobilissimos ojos de la cara y zvrriago contra el abogado del nefando ojo del culo / Escriviólas el bachiller Polvorin de Tras-teriego. [Madrid: s.n., s.a.]. 8 p.; 4º Signatura: XVII/773(4). 


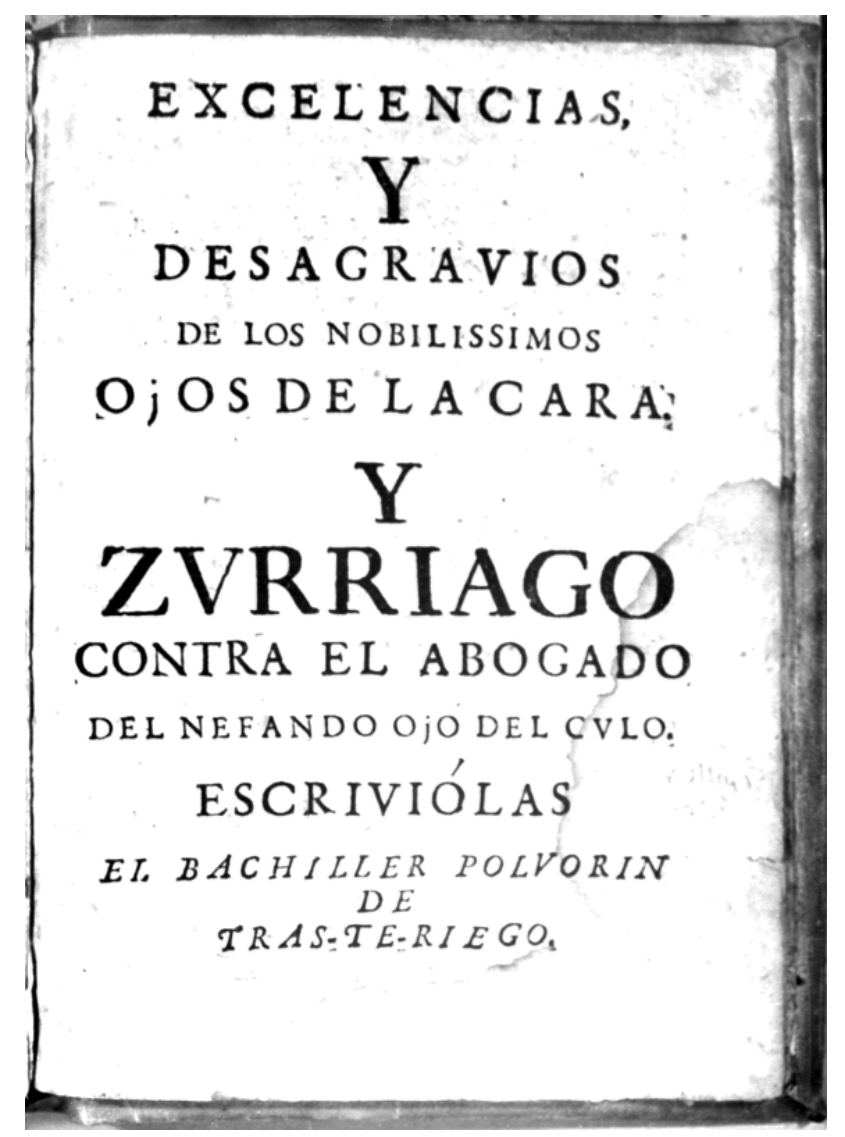

Lámina 2. Portada de la invectiva contra Gracias y desgracias del ojo del culo de Quevedo.

5. El examen del prado. [S.1. : s.n., 166-?]. 15 p., 4º. Signatura: XVII/773(5)

Según el índice manuscrito que consta en la primera hoja del volumen, el facticio contenía en origen dos obras más, aparentemente perdidas por avatares de la transmisión textual, y entre las que se cuenta una de las dos invectivas conocidas de Juan de Jáuregui: "El retraydo contra Quevedo" y "El Alma de Trajano del P. Montalvo". Como explican responsables de la biblioteca, el volumen "llegó muy deteriorado y sin esas dos obras". En lo que atañe a su origen, y según consta en una anotación manuscrita realizada en la hoja de guarda, "el libro perteneció a D. José Mayans y Mayans, Conde de Frigona y a Cesare Malfatti, ya que su ex-libris está también”. El volumen fue adquirido y restaurado por la Biblioteca Valenciana, donde hoy se conserva. ${ }^{6}$

No es propósito central de este artículo, pero conviene detenerse fugazmente en el tercer texto del volumen, la obra de Quevedo, debido a la rareza de este ejemplar

\footnotetext{
${ }^{6}$ Deseo expresar mi agradecimiento a Emma Gómez-Senent López, técnico del departamento de fondo antiguo y manuscritos de la Biblioteca Valenciana Nicolau Primitiu (Monasterio de San Miguel de los Reyes), por su amabilidad y la valiosa información facilitada sobre el volumen facticio.
} 
nunca descrito. Existe uno en la Hispanic Society of America (HSA), el único utilizado en ediciones críticas de Gracias y desgracias, y está en paradero desconocido otro que pudo haberse encontrado en la Biblioteca Nacional de España: fue citado por Fernández-Guerra -quien consideró que los ejemplares de esta edición "son rarísimos hoy" (1852, p. 484, nota a)- y críticos posteriores. ${ }^{7}$ El que he localizado en la Biblioteca Valenciana se convierte, pues, en el segundo de esos raros ejemplares de la impresión.

El impreso de Gracias y desgracias del ojo del culo encuadernado junto con la invectiva Excelencias y desagravios carece de las páginas 13 y 14 (pasa de la 12 a la 15), pero reconstruye su texto perdido insertando tres folios con caligrafía del siglo XIX, copiándolo a partir de un manuscrito, presumiblemente alguno de los tres que entonces se conservaban en la $\mathrm{BNE},{ }^{8}$ como se deduce de la siguiente indicación, al final de la parte manuscrita: "Julio de 1858, copiado en la Biblioteca Nacional, de un ms., dictándome el Sr. Director, D. Juan Eugenio Hartzenbusch, por no haberlo impreso".

Según tales indicios, el ejemplar hoy custodiado en la Biblioteca Valenciana podría ser el citado en el "Catálogo de ediciones de obras de Quevedo" de FernándezGuerra (1852, p. XCIII, número 10), con datación estimada en 1626 y en aquel momento guardado en la BNE: “dos pliegos de impresión en $4^{\circ}$, sin año ni lugar". De acuerdo con la información del editor, "de ellos [los ejemplares rarísimos de la edición de la obra a que acaba de referirse] existe uno en la Biblioteca Nacional, y también tres copias manuscritas con variantes notables" (1852, p. 484, nota a).

La parte mutilada del impreso de Gracias y desgracias se corresponde con el final de las "gracias" y el comienzo de las "desgracias", en concreto las seis primeras. Es imposible saber si esta pérdida de páginas se produjo ya en el siglo XVII o con posterioridad; de haberse tratado de una mutilación contemporánea y de haber manejado este ejemplar el autor de la invectiva, se explicaría que se hubiese centrado en las "gracias" y no hubiese comentado ninguna "desgracia", una mera hipótesis por ahora.

\footnotetext{
${ }^{7}$ Azaustre (2007, p. 484), que se basó en el único ejemplar que conocía, el de la HSA, reconoció que "no he encontrado el de la Biblioteca Nacional de España" y recordó que, según Jauralde, Eugenio Asensio poseyó un ejemplar de esa edición.

${ }^{8}$ Hoy son cuatro, con signaturas Ms. 2341, Ms. 4067, Ms. 17581 y Ms. 20074, folleto 52. Por innecesarias para el objetivo de este artículo, evito aquí posibles especulaciones sobre el manuscrito que pudo ser utilizado como modelo.

${ }^{9}$ Fernández-Guerra (1852, p. 484) eludió incluir Gracias y desgracias del ojo del culo en su edición de las obras de Quevedo, por razones morales: sólo consignó el título y el comienzo.
} 


\section{Datación de la invectiva}

La invectiva inédita hubo de componerse en un momento muy cercano al de la difusión impresa de Gracias y desgracias del ojo del culo: así se deduce de las palabras iniciales del texto, donde se da noticia de la publicación y divulgación de la obra burlesca de Quevedo en el ámbito de la Corte:

Entre tantos abortos como del descuido de la naturaleza se han originado, tengo por sin duda ser uno el parto del autor que estos días pasados nos ha infestado el aire de los apacibles climas de esta Corte con los pestíferos y nefandos acentos que por toda ella han resonado, procedidos de un papel impreso -que ya habrá parado en donde trae su origen-, cuyo título era Gracias y desgracias del nobilísimo ojo del culo (p. 2)

El ataque debió de ser anterior al contenido en otras invectivas conocidas y datadas que también desacreditan las Gracias y desgracias: la Venganza de la lengua española, publicada en Huesca por Pedro Blusón en $1629,{ }^{10}$ y El tribunal de la justa venganza. ${ }^{11}$ Los escritos contra Quevedo van acumulando, a lo largo de los años, nuevas obras sometidas a escarnio, a partir de la Venganza: ${ }^{12}$ dado que las Excelencias $y$ desagravios se centran en exclusiva en Gracias y desgracias, es posible que aún no se hubiese producido la impresión de textos literarios como Política de Dios y el Buscón (1626), los Sueños (1627) o La Perinola (h. 1632), ${ }^{13}$ dianas preferentes de los discursos satíricos, junto a otras obras quevedianas.

Los críticos que han estudiado Gracias y desgracias han propuesto una época de redacción para este texto burlesco que fluctúa entre los años 1620 y 1626: FernándezGuerra (1852, p. 484, nota a) se inclinó por una fecha temprana, 1620, a juzgar por los datos contenidos en una de las fuentes manuscritas, aunque en su catálogo de obras amplía el abanico de fechas posibles desde la citada hasta 1626 (p. LXXXV, no 76). García Valdés (1993, p. 92) sugirió para la obra un momento comprendido entre 1620 y 1626, como lo hizo Jauralde (1983, pp. 280-281, nota 33), quien fijó la escritura a partir de 1620 y antes de 1626, tomando en consideración la información de las fuentes textuales y la fecha de la Venganza de la lengua española. Azaustre (2007, p. 482) apuntó una datación aproximada en torno a 1620. En lo que atañe a la fecha concreta de la única fuente impresa de época conocida, Astrana (1932, pp. 1378-1379, no 40) la data

\footnotetext{
10 "No puedo disimular en este paso aquel inmundo discurso (que todo parecía cámara) de las Excelencias $y$ desgracias del culo" (Alonso de Laureles 1932, p. 1042), se lee en este impreso.

${ }^{11}$ En esta invectiva, la obra se cita como "Gracias y desgracias del culo" (Franco-Furt 1932, p. 1106).

12 Véase, sólo por ejemplo, la relación de títulos quevedianos incluida en la primera audiencia, cargo cuarto, de El tribunal de la justa venganza (Franco-Furt 1932, p. 1106).

13 Puede consultarse Plata (2006 y 2017), además de otros trabajos del mismo crítico.
} 
en 1629 , mientras que Palau (1962, p. 384, $\mathrm{n}^{\circ}$ 243847) se inclina por 1628 como fecha de la edición; Buendía (1978, pp. 1278 y 1280) parece oscilar entre 1628 y 1629.

Teniendo en cuenta la cronología imprecisa reiterada por la crítica, sólo cabe concluir que el momento de impresión de la invectiva estuvo próximo al de la edición de la obra de Quevedo y proponer su posible condición de pionero entre los escritos directos contra el escritor, o al menos uno de los más tempranos, habida cuenta de que no menciona algunos de los que, a partir de 1626, se convierten en asunto central de las diatribas posteriores.

No obstante, la Venganza de la lengua española se congratula de que Gracias y desgracias aún no hubiese sido publicada. ${ }^{14}$ Este dato obligaría a retrasar la fecha de impresión de la obra burlesca de Quevedo, y la de la invectiva inédita, por lo menos hasta ese momento, pero lo cierto es que nada impide que quien hacía tales consideraciones no hubiese tenido noticia aún del texto impreso.

Las coincidencias exactas con el impreso del siglo XVII, en una obra marcada por la complejidad textual derivada de una profusa tradición manuscrita con abundantes variantes (sobre todo en el apartado de las "desgracias"), animan a pensar que fue ésta la que siguió el autor de la invectiva. No parece probable una datación más tardía, como posible respuesta contra versiones de la obra publicadas ya en los siglos XVIII y XIX, ${ }^{15}$ porque todos los indicios internos del texto, relativos al contexto de escritura y difusión, apuntan a que Quevedo estaba aún vivo y se pretendía zaherirle personalmente, al tiempo que se le descalificaba como escritor. A ello se suma la propia catalogación, en el siglo XVII, realizada por la biblioteca en la que se custodia.

\section{Un pseudónimo jocoso}

No existe en el impreso ningún dato o alusión que permita identificar al autor, oculto por el pseudónimo "Polvorín de Tras-Te-Riego", nombre jocoso inventado tras el cual

\footnotetext{
14 "no puedo dejar de estimar el recato con que le ha detenido entre borrones, sin darlo a la impresión" (Alonso de Laureles 1932, p. 1042).

${ }^{15}$ Se trata de los siguientes impresos: Gracias y desgracias del nobilísimo señor ojo del culo, dirigidas a don Chupas de la necesaria, montón de pasas por arrobas. Escritas por el Bachiller don Juan Lamas el del camisón cagado. Con licencia del Doctor Cagarria. Impreso en Cacatecas el año pasado, tal vez editado a comienzos del siglo XVIII y conservado en dos ejemplares de la British Library (signatura 9195.C.21.(6)) y la Biblioteca Nacional de México (Herrera 1999, pp. 271-289); y Gracias y desgracias del ojo del culo por D. Francisco de Quevedo y Villegas, impreso en 1874, y accesible en un ejemplar de la HSA. Debe notarse la coincidencia (tal vez casual o inducida por algún manuscrito) del título de la invectiva con el primero, en el término "nobilísimo", ausente en la princeps de Gracias y desgracias, si no es que existió otro impreso de época que también lo tenía, hoy desconocido.
} 
podría encontrarse cualquiera de los enemigos de Quevedo que, a partir de la tercera década del siglo XVII, hicieron arreciar las críticas contra su literatura. El nombre parece evocar la asociación usual entre el antropónimo y el gentilicio: el término Polvorín apunta a lo incisivo de la sátira, que metafóricamente dispara su pólvora contra el escritor; Tras-Te-Riego, a un lugar ficticio, documentado previamente en un texto teatral, ${ }^{16}$ y tal vez también, basándose en la disociación del término, a los golpes que propina, 'riega', con su invectiva contra las asentaderas a las que Quevedo había elogiado. Avalan tal interpretación las abundantes referencias al zurriago o a los disparos y la pólvora a lo largo del texto:

y así, supuesto lo dicho, ropa fuera (perdone el lector), y ande el culo por alto, y el zurriago tras él (p. 3).

ya está el zurriago a punto, con brioso ademán de sacudille bien el polvo (p. 4)

¡Oh, quien le viera a este autor embestir con una jeringa a un trasero, y más si fuera abrasando, a ver si el ojo del culo le hacía mal de ojo arrojándosela a las barbas y a sus mismos ojos! Ya se ve las veces que habrá sucedido, y que esto no es fuerza del discurrir, sino violencia del disparar. Quien tal hace, que tal pague (p. 6)

Podrá quedar muy pagado, y más si su mismo ojo, celebrando el cariño, hace la salva, soltando la artillería. Que, para que fuera más al propio, fuera bien embocarle por su cañón cantidad de pólvora y demás munición, pero muy poquito fuego por que no se congojase (p. 8)

Debe recordarse que el propio texto vilipendiado, Gracias y desgracias del ojo del culo, se difundió también bajo pseudónimo, "Juan Lamas, el del camisón cagado", como otras invectivas contra Quevedo: “Juan Alonso de Laureles”, en el caso de la Venganza de la lengua española; o el "Licenciado Arnaldo Franco-Furt", en el de El tribunal de la justa venganza.

\section{Estructura del contenido de la invectiva}

Las Excelencias y desagravios de "Polvorín de Tras-Te-Riego" poseen una estructura tripartita: una presentación del escrito que contiene un ataque contra Quevedo y una declaración de intenciones, en la que su autor desgrana argumentos para justificar que vaya a hablar sobre materia tan impropia; un comentario de las más relevantes "gracias" de la obra de Quevedo, para impugnarlas, sin referencia alguna a las "desgracias"; y una conclusión en la que se reitera el loable propósito de la invectiva, para evitar el efecto pernicioso que el escrito quevediano podría ocasionar en "el vulgo inerudito".

\footnotetext{
16 A. Bonilla (1912, p. 52) lo transcribe, con los siguientes versos: "que no era sino crego, / y de allá de Trasteriego / fue señor / y también fue regidor" (vv. 214-217).
} 
El texto comienza con una mención directa de la obra burlesca denostada, calificada como "aborto" originado por "descuido de la naturaleza", de "pestíferos y nefandos acentos", y acusa a su autor de haber "infestado el aire de los apacibles climas de esta Corte". El párrafo inicial no sólo cita explícitamente el objetivo del escrito, sino que ofrece datos que permiten identificar el contexto y el momento en que se produce: la referencia a "estos días pasados" apunta a una redacción inmediatamente posterior a la difusión del impreso de Quevedo; por otra parte, el desconocido autor de la invectiva declara haberse basado en la mencionada fuente textual, cuando se refiere a "un papel impreso [...] cuyo título era Gracias y desgracias del nobilísimo ojo del culo".

A continuación, la invectiva justifica el contenido de las Gracias y desgracias en el nacimiento indigno de su autor:

habiendo este autor nacido por aborto de naturaleza, por el ojo que tanto celebra, le quedó la nativa propensión de revolcar su pensamiento en aquel asqueroso conducto (p. 2)

Los párrafos que siguen reflexionan sobre el contraste entre la grandeza de los ingenios de la Corte de España y la circulación de "discursos tan soeces, voces tan impuras, ocupaciones tan pésimas y sin fruto" (p. 2), un hecho que a su juicio no cabe justificar por el supuesto destinatario, la "gente ordinaria" (p. 2). Pero la parte más extensa de esta introducción se destina a salvaguardarse de posibles acusaciones de incurrir "en lo mismo que impugno" (p. 3); el último de los cargos que se le podrían hacer, el que pueda resultar en "grande mengua mía el ponerme a reñir con un cagado" (pp. 3-4), incluye un doble apodo jocoso para el "autor del tratado del ojo del culo" (p. 3): "Bachiller Clarete" (p. 3), en probable alusión a la fama de borracho que algunas invectivas habían hecho recaer sobre Quevedo, ${ }^{17}$ y "señor Pedaneo" (p. 4), posible dilogía referente tanto al regidor con jurisdicción limitada como a las ventosidades del ojo al que había elogiado.

A partir de este punto, comienza la refutación de las "gracias" enumeradas por Quevedo: su nobleza, su imperio y veneración, su forma circular favorecida, su tacto blando, su proximidad a los cíclopes, su ventaja, su mayor limpieza y su mayor necesidad respecto a los ojos de la cara, su alejamiento de los vicios y escándalos del mundo y su falta de implicación en el mal de ojo en que incurren aquéllos. Esta segunda

\footnotetext{
${ }^{17}$ Puede recordarse el soneto atribuido a Góngora "Cierto poeta, en forma peregrina": "a Brindis sin hacer agua navega / Este sin landre claudicante Roque, / de una venera justamente vano / que en oro engasta, santa insignia aloque, / a San Trago camina, donde llega, / que tanto anda el cojo como el sano" (2015, pp. 549-550, vv. 9-14). Y también la Sátira contra don Francisco de Quevedo que comienza "-¡Oh Musa! Dime, ¿quién es”, donde se lee “¿Quién más borracho que un mico”.
} 
parte traza en su segunda mitad los "desagravios de los nobilísimos ojos de la cara" (p. 1), apelando a su condición de "astros de este mundo pequeño" (p. 6) y a su superioridad respecto al resto de los sentidos, que "les eleva a la línea intelectiva" (p. 7).

El texto concluye como había comenzado, con una nueva consideración sobre el propósito de la invectiva ("que al vulgo inerudito y de mal gusto se le abran los ojos para no tropezar en el que tanto alaba esta buena pesca de tan cenagoso pantano”, p. 8), justificando su brevedad con dos argumentos: su indignidad para tener como destinatarios a cortesanos e ingenios (por la materia tratada y el texto al que sirve de impugnación) y la superfluidad de utilizar argumentos para probar "una cosa tan clara" (p. 8).

\section{Transcripción de la invectiva}

A continuación se edita el texto de la invectiva, modernizado en ortografía y puntuación.18 Se incluye a pie de página la referencia de los lugares de las Gracias y desgracias de Quevedo comentados por el desconocido "Polvorín de Tras-Te-riego". ${ }^{19}$

\section{Excelencias y desagravios de los nobilísimos ojos de la cara, y zurriago contra el abogado del nefando ojo del culo}

\section{Escribiolas el bachiller Polvorín de Tras-Te-Riego}

Entre tantos abortos como del descuido de la naturaleza se han originado, tengo por sin duda ser uno el parto del autor que estos días pasados nos ha infestado el aire de los apacibles climas de esta Corte con los pestíferos y nefandos acentos que por toda ella han resonado, procedidos de un papel impreso -que ya habrá parado en donde trae su origen-, cuyo título era Gracias y desgracias del nobilísimo ojo del culo. Ojo al ojo, y ojo a lo dicho, que este ojo, en mi entender, debió de ser, por yerro de cuenta, el conducto de su nacimiento.

Asienten muchos que el estímulo que tanto acosa al hombre, en orden a inficionar su pensamiento con objetos impúdicos del sexo femíneo, no sólo consiste en

\footnotetext{
${ }^{18}$ Dado el espacio limitado de un artículo y que el propósito básico es dar a conocer un texto inédito, no he considerado oportuno incluir anotación filológica ni tampoco un estudio textual que haga referencia a las distintas versiones de las Gracias y desgracias, con una profusa tradición manuscrita. Preparo ya una edición crítica y anotada de la invectiva, de próxima publicación, que se ocupará de tales asuntos. ${ }^{19}$ Las citas que incluyo de la obra de Quevedo remiten a las páginas del impreso de época cuya difusión determinó la publicación inmediata de la invectiva, en este caso a través del ejemplar localizado también en la Biblioteca Valenciana, aunque modernizo ortografía y puntuación; al lado incluiré el número de página en la edición moderna de Azaustre (2007), para una más cómoda verificación de dichos lugares.
} 
la natural inclinación que a la generación tiene, sino también en aquel nativo respecto que dice al origen de donde procedió; de donde infiero que, habiendo este autor nacido por aborto de naturaleza, por el ojo que tanto celebra, le quedó la nativa propensión de revolcar su pensamiento en aquel asqueroso conducto y anteponerle en sus excelencias (¡qué obscena locura!) a los ojos de la cara.

Yo no me admiro de que, habiendo tantos monstruos de naturaleza, los haya también en los ingenios, pero sí, y mucho, de que en una Corte de España donde con tanto decoro brilla la grandeza, a quien se debe toda respetosa atención -florecen ingenios tan relevantes, cuya censura tiembla aun el más acreditado; políticos tan cortesanos, cuyo ceño castiga no sólo lo indecente sino también lo superfluo y mal limado-, se permitan discursos tan soeces, voces tan impuras, ocupaciones tan pésimas y sin fruto que, aunque quieran decir que esto sólo es un pasatiempo, pasen los tales que lo dicen y sepan que, para ministrarle divertimientos al ocio, hay mucha diversidad de materia de donde formar objetos decentes para recreo de los ingenios y de los que se divirtieran con sus obras.

Ocurro también al descargo que puede tener alguna apariencia de disculpa, y es que antes se infiere de aquí la grandeza de esta Corte, donde residen tantas clases de sujetos, que no es la de menor número la inferior y más común, y que así este autor guisó este plato para gente ordinaria, a quien no dan gusto cosas de más primor. Muy buen provecho les haga. Pero tampoco es ésta bastante disculpa, porque aun para esta gente puede haber más copiosa y bastante materia en línea más decente que les entretenga, como parece en tantos papeles, coplas y relaciones como andan impresas, claras y de buen gusto, que al más zafio pueden servirle de divertimiento y aun de doctrina.

También ocurro a un cargo que se me puede hacer de que yo incurro en parte en lo mismo que impugno, supuesto que, tocando en cosa tan asquerosa aunque sea para redargüirla, es fuerza que me empringue y que ofenda los oídos del lector con las voces impuras que es preciso repetir. Así es verdad porque, si el autor escribió -que es lo que más puedo alegar en su favor- para la gente más común y de más basto discurso, es necesario para que lo entiendan usar de las voces en la misma línea de claridad que él las pone, pues no dudo pudiera yo muy bien rebozarlas con términos más decentes y prosa limada. Pero era lo mismo que no conseguir mi intento, que es desengañar a estos mismos para quien supongo escribe, del mal gusto y pésima ocupación que han tenido a 
costa de su dinero, porque me persuado que personas entendidas de más alta jerarquía rara (o ninguna) habrá sido la que se haya alhajado de un papel tan asqueroso, con que para estos no puedo yo tampoco escribir, pues en esta suposición no estarán noticiosos de la [obrilla $]^{20}$ de este sujeto, con que, escribiendo para estos últimos, estoy precisado a acomodarme a las voces bajas y soeces de que él usa, para que me entiendan.

Bien sé que todavía no he satisfecho al cargo de que yo mismo me he hecho fiscal, porque aún no había llegado el punto de responder. Ahora lo hago, y digo que, cuando un fuego se emprende en un edificio, es muy loable y aun necesario el acto de caridad urgente de acudir a apagarle; lo que se intenta es que aquel fuego no abrase ni cunda, y el que quiere oponerse al incendio no puede menos de lidiar con el fuego mismo, expuesto a abrasarse o a lo menos a chamuscarse. Así digo yo ahora, para oponerme a esta peste de tan soeces asuntos y voces, y que no cunda entre gente sencilla de poco discurso o a lo menos estragado, es preciso que la misma materia contra quien peleo me deje marcado, lleno de manchas, con necesidad (en acabando) de jabonarme de pies a cabeza y echarme en colada. Lo segundo, respondo que, cuando se pone un precepto negativo en que se prohíbe alguna cosa mala o indecente, usa el legislador de los mismos términos y voces que declaran lo mismo que se prohíbe; y así, supuesto lo dicho, ropa fuera (perdone el lector), y ande el culo por alto, y el zurriago tras él.

Pero antes de comenzar quiero responder a otro cargo que también pueden hacerme, el cual he dilatado hasta este punto de haberme tomado la licencia del Bachiller Clarete: y es que, si el autor del tratado del ojo del culo, siendo aborto de naturaleza, nació por él -según que se probó arriba-, es grande mengua mía el ponerme a reñir con un cagado. No lo niego, pero para todo hay remedio, que, con darle un buen jabón aunque sea de Palencia, como hacen las lavanderas a las camisas cargadas de palominos, le pondremos de forma que sin asco se le pueda echar la garra.

¡Ea, caballero mío! ¡Oxte, puto! Y qué mal comienzo. Vuélvome a engullir la palabra, que es muy escrupulosa en la ocasión presente; y así, póngasele un ojo al caballero, y en su lugar se diga Pedaneo, con exclusión del mío, porque no quiero me linsonjee las narices con sus perfumes. Ea, señor Pedaneo -que así quedamos-, venga vuesa merced a juicio y trate de desatacarse, para que veamos el original de su obra, que ya está el zurriago a punto, con brioso ademán de sacudille bien el polvo.

\footnotetext{
${ }^{20}$ No consigo leer con claridad esta palabra: el uso de tipos desgastados en la imprenta provoca una falta de nitidez de los caracteres en muchos lugares del impreso.
} 
Lo primero, dice que el ojo del culo es más noble ${ }^{21}$ que todos los demás miembros del cuerpo. Miren si digo yo bien, que fue estornudo de aquel inmundo albañar, pues trabaja y afana tanto en probar la nobleza de su origen, pero fáltale el acompañarla de servicios, porque, sin ellos, no podrá pasar plaza de pretendiente. Quien tal hace, que tal pague: jzurra y andar!

Dice también que el ojo del culo tiene más imperio y veneración ${ }^{22}$ que todos los demás miembros del cuerpo humano. Vámoslo viendo, que yo tengo para mí que una de estas cosas prueba, y la otra la da a probar: prueba ser grande su imperio, pues le tiene en los reinos y lugares de Galicia, Holanda, Daroca y otros en quien hace sus provisiones. La otra cosa que dice tiene más veneración; creo, sin duda, será yerro de pluma de las muchas que se le sueltan, y así, donde dice tiene más veneración, ha de decir que da más veneración, porque, si la veneración se explica en ofrecer humos, él lo hace a todo su cuerpo y aun a los circunstantes, con los perfumes que de continuo evaporiza. Prosigue diciendo que es más favorecido de la naturaleza por ser su forma circular; ${ }^{23}$ también lo es la boca de un cañón y una bala, fuera de que circular y ojo de culo allá se va todo, que el mismo nombre dice su forma, aunque yo -según mi dictamen- le llamara mejor orbicular, que hace dos sentidos ajustados: el primero es que, siendo el hombre mundo pequeño -como hemos dicho-, si orbe es lo mismo que mundo, orbicular querrá decir culo del mundo; y en cuanto a su forma, si orbe quiere decir cosa redonda o redondez, orbicular será lo mismo que culo redondo. Pero estas etimologías quédense para cabezas redondas, que aquí no nos importa el que sea redondo o cuadrado, ni por ahí puede explicarse su excelencia, pues muchas cosas hay redondas que son de suyo bien infames. Quien tal hace, que tal pague: ¡zurra y andar!

Prosigue sus excelencias con decir que es su tacto blando. ${ }^{24}$ Miren qué milagro, con tantos barnices, mermeladas y ungüento amarillo como percibe de la botica de los

\footnotetext{
21 es más noble: se refiere al comienzo de la obra de Quevedo: "No se espantarán de que el culo sea desgraciado los que supieren que todas las cosas aventajadas en nobleza y virtud corren esta fortuna de ser despreciados della" (p. 5; p. 505).

22 tiene más imperio y veneración: “y él en particular, por tener más imperio y veneración que los demás miembros del cuerpo" (p. 5; p. 505).

${ }^{23}$ más favorecido de la naturaleza por ser su forma circular: "es el más perfecto y bien colocado dél, y más favorecido de la naturaleza, pues su forma es circular, como la esfera, y dividido en un diámetro o zodíaco, como ella" (p. 5; pp. 505-506).

24 es su tacto blando: "su tacto es blando" (p. 5; p. 506).
} 
intestinos. Que se parece a los cíclopes por tener un solo ojo: ${ }^{25}$ pues váyase a la fragua de Vulcano, que allí topará la horma de su zapato. Que es más de ver que los ojos de la cara: ${ }^{26}$ lástima es que a este autor no se los saquen y, si ser pudiera, le pusieran en la frente su ojo de culo, pues, siendo cosa tan de ver como dice, allí lograra el ser objeto franco para todos, saboreándose en los aplausos de su hermosura. Es tanta su hedionda manía que asegura es más limpio el ojo del culo que los mismos ojos: ${ }^{27}$ esto no merece más respuesta que decirle -en suposición de lo que dijo arriba, que era un señor de grande imperio y nobleza- bese sus provisiones y se recree pasando los ojos por las pruebas de su limpieza. Quien tal hace, que tal pague: ¡zurra y andar!

Sube el grado de su calificación con decir que el ojo del culo es más necesario que los ojos de la cara, ${ }^{28}$ y de aquí saca por consecuencia su nobleza. Más necesario es el verdugo para la justicia que los señores jueces que la pronuncian; pruébolo porque, si el verdugo no ejecutara la sentencia que dan los jueces, la justicia se quedara empapelada y, faltando la ejecución, faltaba todo. ¿Saldrá por consecuencia, luego, es más noble el verdugo que los alcaldes y jueces? ¡Qué grosera necedad! El ojo del culo es la necesaria del cuerpo humano; por allí pasan las más asquerosas inmundicias que expele. ¿Será bueno, alabando un edificio de un palacio, que los albañares y letrinas que tiene es lo más principal y lo más hermoso que todas las demás partes que le construyen? ¿Que un hermoso ventanaje, portadas, colunas, basas, linteles, frisos y fachadas vistosas, con toda la demás artificiosa corpulencia del edificio, no iguala a la nobleza y excelencia de sus albañares inmundos? ¿Puede haber mayor desatino? Pues la misma consecuencia sale, según el juicio perdido de este autor, respecto del edificio del hombre.

\footnotetext{
${ }^{25}$ Que se parece a los ciclopes por tener un solo ojo: "tiene un solo ojo, por lo cual algunos le han querido llamar tuerto; y, si bien miramos, por esto debe de ser alabado, pues se parece a los cíclopes, que tenían un solo ojo y descendían de los dioses del ver" (p. 5; p. 506).

${ }^{26}$ Que es más de ver que los ojos de la cara: "Fuera de que el ojo del culo, por su mucha gravedad y autoridad, no consiente niña; y, bien mirado, es más de ver que los ojos de la cara, que, aunque no es tan claro, tiene más hechura" (p. 5; p. 506).

${ }^{27}$ es más limpio el ojo del culo que los mismos ojos: "y no los de la cara, que no hay paja que no los haga caballeriza, ni polvo que no los enturbie, ni relámpago que no los ciegue, palo que no los tape, ni caída que no los atormente, ni mal ni tristeza que no los enternezcan" (p. 6; p. 508).

${ }^{28}$ es más necesario que los ojos de la cara: "De más de que hallaremos que es más necesario el ojo del rabo solo que los de la cara, por cuanto uno sin ojos en ella puede vivir, pero sin ojo del culo ni pasar ni vivir" (p. 6; p. 508).
} 
Métese también a moralista y dice que a los ojos de la cara los buenos cristianos los llaman ventanas del alma, por donde ella bebe el veneno de los vicios. ${ }^{29}$ Dígame, buen cristiano, si el ventanaje de una casa tiene sus puertas y cortinas para defensa de las inclemencias del tiempo, y por el descuido de sus habitadores quedan unas sin cerrar y otras sin correr, de que se sigue el entrarse en las salas y aposentos, ya los calores en el verano ya lo borrascoso de las lluvias en el invierno, con que todo lo interior se destempla, ¿qué culpa tienen las ventanas? Los ojos de la cara los formó Dios sobre toda su hermosura con tan pulida y hermosa defensa que los adornó de párpados y pestañas, para que pueda el hombre cerrar y abrir a su tiempo, según la oportunidad de las ocasiones, siendo el dictamen de una buena razón el superintendente y como alcaide de las puertas de este alcázar, para cerrarlas y abrirlas cuando la ocasión lo pida. Pues, ¿qué culpa tendrán los ojos de que por sus ventanas se entre al alma el veneno de los vicios, si el sumiller que ha de cerrar las cortinas se descuida? Los ojos no se defienden de que los cierren ni dejen abiertos: siempre están obedientes a lo que ordenare la razón que se haga, a cuya disposición tiene sujetos sus movimientos. Pues, ¿para qué se ha de echar la culpa a quien no la tiene? Prosigue diciendo que, cuando por el pacífico y virtuoso ojo del culo hubo jamás escándalo en el mundo, ${ }^{30}$ siendo así que ha sido en muchos el instrumento de los escándalos mayores y más nefandos que ha habido en el orbe; que, aunque -según de lo que llevo dicho- se infiere no tiene por sí este miembro la culpa, porque también se deja gobernar y está sujeto al albedrío de cúyo es, pero, regulándolo según el consecuente sentir de este autor, si los ojos de la cara son las ventanas del veneno que entra en el alma, y por eso les culpa sin tenerla, también puede culpar al ojo que tanto alaba de las abominables y escandalosas deformidades que por él han sucedido.

Dice también en su alabanza que jamás ha hecho mal de ojo como los de la cara. ${ }^{31} ¡ \mathrm{Oh}$, quien le viera a este autor embestir con una jeringa a un trasero, y más si fuera abrasando, a ver si el ojo del culo le hacía mal de ojo, arrojándosela a las barbas y

\footnotetext{
${ }^{29}$ ventanas del alma, por donde ella bebe el veneno de los vicios: "Lo otro, sábese que ha habido muchos filósofos y anacoretas que, para vivir con castidad, se sacaban los ojos de la cara, porque comúnmente ellos y los buenos cristianos los llaman ventanas del alma, por donde ella bebe el veneno de los vicios" (p. 6; p. 509).

${ }^{30}$ por el pacífico y virtuoso ojo del culo hubo jamás escándalo en el mundo: "Por ellos hay enamorados, incestos, estrupos, muertes, adulterios, iras y robos; pero, ¿cuándo por el pacífico y honrado ojo del culo hubo escándalo en el mundo, inquietud ni guerra?" (p. 6; p. 509).

${ }^{31}$ jamás ha hecho mal de ojo como los de la cara: "Pruébenle al ojo del culo que ha muerto muchachos, caballos, perros; que ha marchitado yerbas y flores, como lo hacen los de la cara, mirando lo ponzoñoso, que son por lo que dicen que hay mal de ojo" (p. 6; p. 510).
} 
a sus mismos ojos! Ya se ve las veces que habrá sucedido, y que esto no es fuerza del discurrir, sino violencia del disparar. Quien tal hace, que tal pague.

Son los ojos de la cara los astros de este mundo pequeño -que así llaman al hombre- formados con tanto primor del Soberano Artífice que, si pudiera haber en su obrar más o menos ciencia y ocupación, pudiéramos decir que en estos dos luminares tan sotiles había echado todo el resto de su saber, con dilatada ocupación de lo prolijo en su obrar. Son dos joyas tan hermosas y tan -digámoslo así- de filigrana que en su género no puede haber cosa más delicada y perfecta. No tiene el alma mayor recreo en la cárcel de este cuerpo (abstraigo de lo que toca a la porción superior intelectiva) que estas dos hermosas ventanas, con sus cristalinas vidrieras, señoreándose en medio, en un perfectísimo círculo, las dos pupilas o niñas, con tanta soberanía y real majestad que las pestañas son sus arqueros, y los párpados, sumilleres de su grandeza. No tiene el alma lengua por donde mejor explique sus sentimientos que por los ojos. Cualquier género de pasión que en el alma reina, sea en línea de cariño o enojoso ardimiento sea, son los ojos por donde se manifiesta mejor que por el conduto orgánico de las voces. ¡Qué flechas no despiden cuando el amor reina en el alma! ¡Qué arpones no disparan, cuando el odio y rencor la tienen poseída! Consúltese a sí mismo el más herido de estas pasiones, y díganos cuál es la cosa que más se le imprime en el alma: o la voz que despide el labio o el activo movimiento de los ojos. Es cierto que, si no tuviéramos por cosa de fe que es sola una alma la que nos anima, dijéramos que los ojos la tenían muy propia y especial; a lo menos, es evidente que ningún miembro de todo el cuerpo humano la participa tan de lleno ni con tan vivos efectos como los ojos. ¡Qué hablar tan dulce cuando amorosos miran! ¡Qué retóricos se muestran, dando mil almas a lo que la lengua pronuncia! ¡Qué veneno no despiden, cuando la pasión de unos celos o de un colérico ardimiento ocupa la interior plaza! No hay intérprete ni abogado que más fielmente traslade el afecto que en el alma reina al conocimiento del sujeto a quien le dirige que los mismos ojos. Ojos con ojos se entienden: unos hablan, y otros responden.

Todos los demás miembros sobre lo vegetable participan solamente de lo sensitivo, pero los ojos gozan de un superior privilegio, que les eleva a la línea intelectiva. Son reyes entre los demás sentidos, y sin ellos parece que los demás no tienen el complemento debido de sus operaciones. Dígalo el común uso de hablar, pues lo es el decir: huele y ve qué hermosa es esta flor; gusta y ve qué sabroso es este manjar; oye y ve qué perfecta y sonora es aquella música; toca y ve qué suave es esto. Que, 
aunque es verdad, filosóficamente hablando, que aquel ver significa entender, aun en esto se muestra más la excelencia de este superior sentido, pues a él se le libra la explicación del entender; de manera que se nos manifiesta que, para que las operaciones de los demás sentidos queden del todo perfectas, necesitan de que salgan como selladas y aprobadas del sentido de la vista.

¿Tiene el amor, o el amante que le tiene, en la ponderación de su cariño término más significativo que llamarle mis ojos al objeto de su querer? Más te quiero -se dice comúnmente- que a mis ojos. Y cuando a un niño le preguntan sus padres "Hijo, ¿qué tanto me quieres?", la respuesta es casi siempre: "Más que a las niñas de mis ojos, más que a los ojos de la cara".

Paréceme que, si el autor de las excelencias y gracias del ojo del culo requebrara a una dama, respecto de anteponerle al sentido visible, consiguientemente la había de decir: "Más te quiero que a mi ojo de culo". Y con eso quedara ella muy airosa y favorecida, y toda la expresión de su cariño se resolviera en decir: "Ojo mío de mi culo". Y a sus hijos, si los tiene, les enseñara que, en preguntándoles cuánto le quieren, respondan: "Más que a mi ojo de culo". Podrá quedar muy pagado, y más si su mismo ojo, celebrando el cariño, hace la salva, soltando la artillería. Que, para que fuera más al propio, fuera bien embocarle por su cañón cantidad de pólvora y demás munición, pero muy poquito fuego por que no se congojase.

¿Qué alabanzas, qué elogios, qué retóricos colores en letras, así divinas como humanas, no se hallan en la celebración de los ojos? Que en las humanas corriera esto no hubiera qué admirar, pero tanto y tan de buen gusto como se halla en las divinas, es cosa que basta a calificar estos hermosos soles por la obra de más primor que salió de las manos del Soberano Artífice. Lástima es que la contraposición tan fea de esta impugnación tan justa no me permita el poder hacer un vistoso alarde de la valentía del soberano pincel con que, en las sagradas líneas, se hallan favorecidos los ojos; porque no fuera decente sacar a luz margaritas tan preciosas al lado de tan obscena contraposición. Lo mucho de lo que pudiera hacer aquí ostentación de lo que se halla en las humanas no es para este papel tan corto, porque, suponiendo dos cosas -la primera, el que no es digno, por su mala vecindad, llegue a manos ni de cortesanos políticos ni de ingenios de superior jerarquía; y la segunda, ser cosa superflua y aun ridícula el ponerse a probar de propósito una cosa tan clara-, pongo término a las líneas de mi pluma, pues las breves en que hasta aquí se ha ocupado sólo ha sido con fin de que al vulgo inerudito 
y de mal gusto se le abran los ojos para no tropezar en el que tanto alaba esta buena pesca de tan cenagoso pantano.

\section{Obras citadas}

Alonso Laureles, J. (1932). Venganza de la lengua española contra el autor del "Cuento de Cuentos”, L. Astrana Marín (ed.). En F. de Quevedo, Obras completas. Obras en verso (pp. 1038-1043). Madrid: Aguilar.

Alonso Veloso, M. J. (2015). Los títulos de Quevedo. La Perinola, 19, 111-148.

Alonso Veloso, M. J. (2017). Noticia sobre un manuscrito de El tribunal de la justa venganza. Revista de Filología Española (RFE), XCVII, 1ㅇ, enero-junio, 9-34.

Bonilla y San Martín, A. (1912). Cinco obras dramáticas anteriores á Lope de Vega. Macon: Protat Frères.

Franco-Furt, Arnaldo (1635). El Tribunal de la justa venganza, erigido contra los escritos de don Francisco de Quevedo, maestro de errores, doctor en desvergüenzas, licenciado en bufonerias, bachiller en suciedades, catedrático de vicios y protodiablo entre los hombres. Valencia: Herederos de Felipe Mey.

Franco-Furt, Arnaldo (1932). El tribunal de la justa venganza, L. Astrana Martín (ed.). En Francisco de Quevedo, Obras completas. Obras en verso (pp. 1099-1163). Madrid: Aguilar.

Góngora, L. de (2015). Antología poética, A. Carreira (Ed.). Barcelona: Austral.

Herrera, A. (1999). Quevedo en la Nueva España. Presencia de un conocido texto escatológico de Quevedo en un impreso mexicano del siglo XVIII. Anales del Instituto de Investigaciones Estéticas, 74-75, 271-289.

Jauralde Pou, P. (1999). Francisco de Quevedo (1580-1645). Madrid: Castalia.

Jauralde Pou, P. (1983). Obrillas festivas de Quevedo: estado actual de la cuestión. En Serta Philologica F. Lázaro Carreter, E. Alarcos et alii (ed.). Madrid: Cátedra (II, pp. 275284).

Jáuregui, J. de (1932). El retraído, L. Astrana Marín (ed.). En F. de Quevedo, Obras completas. Obras en verso (pp. 1073-1099). Madrid: Aguilar.

Jáuregui, J. de (1932). Memorial al Rey nuestro señor, Luis Astrana Marín (ed.). En F. de Quevedo, Obras completas. Obras en verso (pp. 1057-1073). Madrid: Aguilar.

Laguna Fernández, J. I. (2016). Luis Pacheco de Narváez: unos comentarios a la vida y escritos del campeón de la corte literaria barroca de Felipe III y Felipe IV, y su supuesta relación con el Tribunal de la justa venganza contra Francisco de Quevedo. Lemir, 20, 211-344.

Morovelli de Puebla, F. (1932). Anotaciones a la Política de Dios, gobierno de Cristo y tiranía de Satanás, L. Astrana Marín (ed.). En F. de Quevedo, Obras completas de don Francisco de Quevedo Villegas (pp. 985-993). Madrid: Aguilar.

Pacheco de Narváez, L. (1932). Memorial denunciando al tribunal de la Inquisición cuatro libros de D. Francisco de Quevedo, L. Astrana Marín (ed.). En F. de Quevedo, Obras completas. Obras en verso (pp. 1043-1050). Madrid: Aguilar.

Pacheco de Narváez, L. (1999). Peregrinos discursos y tardes bien empleadas, Valladares Reguero, A. (ed.). Pamplona: Ediciones Universidad de Navarra (EUNSA).

Pacheco de Narváez, L. (2008). El tribunal de la justa venganza, V. Roncero López (ed.). Pamplona: Ediciones Universidad de Navarra (EUNSA).

Palau y Dulcet, A. (1948 y 1962). Manual del librero hispano-americano. Barcelona-Oxford: A. Palau-the Dolphin Book Co. Ltd.

Plata, F. (2006). La polémica en torno a La Perinola de Quevedo con un texto inédito. La Perinola, 10, 245-255. 
Plata, F. (2017). La transmisión textual de La Perinola de Quevedo. En M. J. Alonso Veloso (ed.), Quevedo en su contexto europeo. Política y religión. Traducciones y textos burlescos (pp. 165-184). Vigo: Editorial Academia del Hispanismo.

Quevedo, F. de (1978). Obras completas Obras en verso, F. Buendía (ed.). Madrid: Aguilar.

Quevedo, F. de (2007). Gracias y desgracias del ojo del culo, A. Azaustre (ed.). En F. de Quevedo, Obras completas en prosa, A. Rey (dir.), II, 2 (pp. 481-525).

Quevedo, F. de (2012). Política de Dios, E. Ma . Díaz Martínez (ed. parte primera) y R. Cacho Casal (ed. parte segunda). En A. Rey (dir.), Obras completas en prosa. Tratados políticos, V (pp. 159-639). Madrid: Castalia.

Quevedo, Francisco de (1852 y 1859). Obras de don Francisco de Quevedo Villegas, A. Fernández-Guerra y Orbe (ed.), 2 vols., BAE 23 y 48. Madrid: M. Rivadeneyra.

Quevedo, Francisco de (1966). Política de Dios, Govierno de Christo, J. O. Crosby (ed.). Madrid: Castalia.

Rey, A. (2014). Lectura del Buscón. Valladolid: Ediciones Universidad de Valladolid.

Tarsia, P. A. de (1988). Vida de don Francisco de Quevedo Villegas, Caballero del Orden de Santiago, Secretario de su Majestad y Señor de la Villa de la Torre de Juan Abad, facsímil de la ed. de Madrid, 1663, rep. M. Prieto Santiago, pról. F. B. Pedraza Jiménez. Aranjuez: Ara Iovis.

Tobar Quintanar, M. J. (2010). La huella de Diego Niseno en El tribunal de la justa venganza. Boletín de la Real Academia Española, 90, 301, 131-159.

Valladares Reguero, A. (1997). Peregrinos discursos y tardes bien empleadas: una obra desconocida de Pacheco de Narváez contra la Política de Dios de Quevedo. La Perinola, 1, 237-256. 


\section{Apéndice}

Texto de la hoja manuscrita, con signatura: XVII/773(3 bis), dispuesta a continuación del ejemplar de Gracias y desgracias del ojo del culo, con letra que parece del siglo XVIII. $^{32}$

Nos, el Doctor D. Pedro Rodríguez de Montanches, catedrático de Prima de Medicina en la Universidad de Salamanca y proto-médico de estos reinos, a todos los que las presentes vieren sarna que rascar, \& Sabed que ante nos pareció la parte de [espacio en blanco para cumplimentar], diciendo que padece humores flatulentos, aéreas morbosidades y epilécticas supuraciones, por lo cual le es conocido perjuicio el detener las ventosidades, según aquello de nuestro Hipócrates: ventositas, si retineatur; qui retinet morietur, \& ideo expellatur. Y, habiendo sido remitida por nos la prueba de esta petición al Dr. [espacio en blanco para cumplimentar] y habernos hecho relación de ser justa su demanda, por tanto y por lo que a nos toca, damos y concedemos licencia al dicho [espacio en blanco para cumplimentar] para que delante o detrás de cualquier persona, de cualquier género, calidad, estado y condición que fuere, pueda, sin contravenir a las leyes de la cortesía, expeler sus ventosidades, con calidad y condición que sea con strepito, dejando su derecho salvo a los circunstantes oyentes para que puedan decir lo de "cuerno y sebo, aguja de espartero, cerote de zapatero", con lo de "por ahí comas carne y por la boca mierda" y "papa te vea la madre que te parió, por que te vea más medrado", "en las sopas lo halles como garbanzo", "por donde salió el pedo, meta el diablo el dedo; la víbora, el pico; el puerco, el hocico; el toro, el cuerno; el león, la mano; su artillería, el borrico; y el remedio del fraile", con todas las demás cláusulas del caso. ${ }^{33}$

Y para que conste adonde convenga, dimos las presentes, firmadas de nuestra mano, selladas con el sello de nuestro oficio, y refrendadas de nuestro infraescripto secretario, en [espacio en blanco para cumplimentar], a [espacio en blanco para cumplimentar], de [espacio en blanco para cumplimentar], del año de [espacio en blanco para cumplimentar].

Por mandado del Proto-Médico mi Señor [espacio en blanco para cumplimentar] Licencia para peer, concedida a [espacio en blanco para cumplimentar]

\footnotetext{
${ }^{32}$ La hoja está diseñada a la manera de diploma jocoso, en el que cabría incluir el nombre del "ilustre" poseedor del privilegio burlesco concedido. Su contenido se relaciona con el de las Gracias y desgracias de Quevedo y parece inspirado por esta obra, tal vez en el siglo siguiente.

${ }^{33}$ Cita, con ligeros cambios, expresiones de Quevedo en el apartado de las "desgracias del ojo del culo".
} 